\title{
Structuring User Experience Design with Affective Concerns
}

\author{
Amic G. Ho \\ School of Arts \& Social Sciences, The Open University of Hong Kong, Hong Kong, China \\ Email: amicgh@gmail.com
}

How to cite this paper: Ho, A. G. (2017). Structuring User Experience Design with Affective Concerns. Art and Design Review, $5,73-83$.

https://doi.org/10.4236/adr.2017.51006

Received: November 21, 2016

Accepted: February 21, 2017

Published: February 24, 2017

Copyright $\odot 2017$ by author and Scientific Research Publishing Inc. This work is licensed under the Creative Commons Attribution International License (CC BY 4.0).

http://creativecommons.org/licenses/by/4.0/

\begin{abstract}
Most current designs are aimed at achieving success in the market. The design industry is generally interested in creating designs that can connect with users. However, not all designs successfully connect with users or create valuable design experiences. Hence, scholars in the discipline of user experience are increasingly investigating user experience mechanisms including the roles of human needs, affective concerns, thoughts, and actions. Studies have revealed that different senses, such as the auditory and visual, are connections influencing design consumption experiences. Such experiences highly influenced user satisfaction with designs. This finding could invoke a shift in the current design trend, from a function-oriented to an experience-oriented approach. Studies have also demonstrated that affective concerns have become a promising aspect of design experience and enhanced the influence of experience on an individual's memory. Hence, affective concerns are crucial factors in the perception of design experience. Studies on design and affective concerns have investigated techniques for intentionally eliciting the affective concerns of users through designed solutions. Thus, the current study aimed to investigate the relationships between affective changes and design outcomes and developed tools for supporting designers in introducing affective concerns in design. In addition, a critical literature review was undertaken to investigate the state of the art in user experience and analyze, compare, and enhance existing knowledge. The investigation revealed the understanding of the affective changes which is one of the important factors to influence the perception of design experience. This understanding is an essential criterion of shaping the design experience for users. Hence, a set of guideline was proposed for generating user experience with affective concerns. It is a tool for designer to shape the design experience with affective concerns of users.
\end{abstract}

\section{Keywords}

User Experience Design, Affective Concerns, Designers 


\section{Introduction}

Research has investigated methods for creating designs that can connect with consumers (Arhippainen \& Tahti, 2003; McCarthy \& Wright, 2004). Current methods for achieving such connections involve combining aesthetic, instrumental, and symbolic functions. Nevertheless, such methods generally focus on the function of design in design consumption, thus constituting the main development direction of the design industry (Fogg, 2002; Hassenzahl, 2006; Mahlke \& Thuring, 2007; Hekkert \& Schifferstein, 2008; Kelly, 2009). Moreover, investigating experience design by focusing solely on design functions is not sufficient. Most designers manipulate the design process from this functional perspective; thus, they neglect aspects such as consumer experience, consequently limiting the opportunities to provide additional design solutions and satisfy users' needs. According to a previous study, consumers received greater satisfaction from the overall design experience than from the functions of design outcomes. This finding inspired scholars to further explore user experience and strategies for designing solutions for users. Studies on design and emotion have suggested that the mechanisms of user experience include the roles of human needs, affective concerns, thoughts, and actions. Different senses, such as auditory and visual experiences, influenced users' experience in design consumption. However, studies investigating techniques for introducing affective concerns into experience design are limited. This study explored how the interactions between users and design outcomes and their enhancement effect on design experiences. Thus, this study investigated methods for optimizing experience design through affective concerns. A new framework of user experience is proposed herein, according to a literature review. This framework illustrates the interactions between users and designers. According to the concept of this framework, the role of affective concerns in experience was examined in an empirical study. Users were recruited to rank the affective concerns they experienced, and the stimulation of their affective concerns by design outcomes was investigated. A design tool was proposed as a reference for eliciting experiences. This tool helped designers to generate experience with affective concerns as they intended. The results are expected to provide a guideline for enriching user experience with affective concerns and inspiring further exploration in design studies.

\section{Human-Design Interactions in Experience Design}

Experience refers to users' or audiences' perception of interactions with people, devices, and events. Clicking on an interesting image online and ordering an item through an app on a mobile phone is two of the numerous formats of interactions. Scholars have investigated the principles of human-design interactions. Nielsen (1994) focused on the interactions among users and tasks; the study evaluated the number of users in design consumption and the quantity of human-design interaction tasks required for creating the most enjoyable experience for users. In Green (2008), a set of empirical measurements was developed for testing users' satisfaction with an interface; the study established quan- 
titative usability specifications such as the number of users using a human-interactive system, the times they had used the system, and the number of errors made during design consumption.

Green (2008) investigated the principle of iterative design. After determining the users and tasks and applying a set of empirical measurements, the experience designer performed the following steps of iterative design: design the user interface; test the design; analyze the results; and finally, repeat all steps until a sensible, user-friendly experience is realized (Green, 2008). Some interactions do not require immediate actions, but instead stimulate audiences' affective concerns. On the basis of the provided insights into experience design, the concept of experience design can be described as follows:

- It is an interaction that is coordinated.

- It is a controlled interaction that reflects the expectation of designers.

A successful experience designer should know their audience or users adequately. In other words, an experience should not focus solely on the implications of usability, visual elements, and physical forms. Experience designers are expected to orchestrate an interactive experience with affective concerns both with and without physical responses.

\section{Role of Affective Concerns in Experience}

Understanding the role of affective concerns in experience is necessary before investigating techniques for introducing affective concerns into experience design. Freud (1937) studied the process of thinking from a psychological perspective. The study revealed the involvement of various types of memory in thinking, namely working memory and long-term memory. Moreover, the study discovered that working memory, which processes information, interacted with longterm memory, which comprises different categories such as individual experience, value and missions, learned knowledge, and skills; the combined memory is recalled and serves as a reference in decision-making. Together, the working and long-term memory guide an individual's judgments, responses, and actions (Craik \& Lockhart, 1972; Longueville, Le Cardinal, Bocquet, \& Daneau, 2003). After an event, individuals use their intrinsic affective concerns and goal relevance to evaluate the event and its outcomes (Scherer, 1997). This process is the primary appraisal stage and initiates the attribution of individuals' responses, which later affect their ability to control their responses. An individual's cultural expectations or norms are involved in the primary appraisal stage. In judgment appraisal, however, designers incorporate their personal affective concerns into the decision-making process, thereby influencing their decision-making abilities (Bandler, Grinder, Stair, \& Bateson, 2005). Examined the structure of experience; the study proposed that "selection", "distortion", and "generalization" are the "three universals of human modeling", which are adopted by individuals for coding and encoding their understanding of experiences. Selection was defined as the filtering of the elements of an experience, distortion is the process of finding areas of emphasis for long-term memory, and generalization is the 
process that shapes the beliefs of the individual. These steps constitute the foundation for applying affective concerns in experience.

\section{Affective Concern Stimulations Shaping Experience through Visual and Auditory Stimuli}

A clear understanding of the relationships between affective concerns, cognition, and motivation is required before exploring the effect of affective concerns on visual communication. Some scholars exploring affective concerns have adopted the psycho-evolutionary concept that affective concerns are evolving evaluative patterns that enable an individual to respond to the external environment quickly and effectively (Nielsen, 1994). Rosenberg (1998) further developed this theory and proposed that a response to affective concerns could be considered as the prior process of judgement and actions. This process could prompt an individual to perceive and categorize critical information from the external environment or events. The process was denoted as an "appraisal process."Moreover, this process is reflected inherently and is based on cognition; it features understanding, interacting with the surrounding environment, and shaping perceptions (Gratch \& Marsella, 2005). Faiola and Matei (2005) also investigated how the dynamics of affective concerns influence an individual's responses on a webbased platform; in the study, a web-based platform was developed by designers of various cultural backgrounds. The research team asked the participants to express their preferences for web-based platforms according to their own bias and affective concerns. When the participants viewed the web-based platforms, their bias and affective concerns engendered 70 types of complex appraisal processes and subjective evaluations (Faiola \& Matei, 2005). The study determined that affective concerns were inextricably linked with users' appraisal of web-based platforms and aesthetic elements in the visual communication they displayed. When the role of affective concerns in the motivation process is understood, the corresponding theories can serve as a reference for further exploring the function of affective concerns in visual communication and their roles in the enhancement of user experience.

Some studies have further investigated how stimulating users' aesthetic experience (i.e., aesthetic elements) elicits users' response through visual communication. Scholars have suggested that some aesthetic elements were applicable for evoking individuals' affective concerns, and that such concerns were changed when they were processing information. Some elements have been identified in studies conducted in the past 10 years. A study on the functioning of aesthetics and preferences in web-based media determined that the arrangement of the design elements influenced the participants' perceptions of the web page design; these perceptions were based on several criteria such as "legibility" and "comprehension" (Schenkman \& Jonsson, 2000). According to the findings of this study, the design integrating pictures and aesthetics garnered a strong preference among users, suggesting that the users' preference for the design elements was influenced by their impression of the "beauty of the pictures (design element)". 
However, the study did not further investigate the effect of specific design elements on affective concern (Gobé, 2001). This effect was first explored by a study on color (Gobé, 2001): Gobé proposed that color served as the element of aesthetics that stimulated aesthetic responses through influencing the neurons in the brain.

Therefore, color schemes that consider an individual's response to particular colors can stimulate specific moods, as discovered by Zettl (1990); the study further explored the influence of color on audiences and determined that the parameters of a color (e.g., from coolness to warmth) could affect mood. In addition to color, studies have investigated the impact of other design elements on users' or audiences' affective concerns. Typefaces have been considered one of the major contributors to aesthetic appeals that influenced affective concerns, as noted in user feedback (Zettl, 1990; Watzman, 2003). On the basis of this feedback, Watzman (2003) created a bold and assertive typographic design. It elicited recognizable responses from the users. In their visual communication design, some design scholars have applied the concept that affective concerns influence response (McCartney \& McCartney, 2014; Lockner \& Bonnardel, 2014). Explored the coding of visual and audio elements in individual learning processes. The studies found that during an experience, users remember the visual and auditory elements they have received. In some situations, the visual and auditory elements may initiate an internal dialogue, through which the individual learns the experience and converts it to long-term memory. These elements would then be adopted as the standard elements and are coded when the individual starts to communicate with others. The message receiver (another individual) recognizes the constructed visual and auditory material through kinesthetic encoding. This process prompts users to engage in interpretation processes.

\section{Model Explaining How Affective Concern Stimulations Shape Experience}

On the basis of the preceding descriptions regarding the relationship between affective concerns and experience design, Figure 1 illustrates a model explaining the mechanism through which affective concern stimulations shape experience.

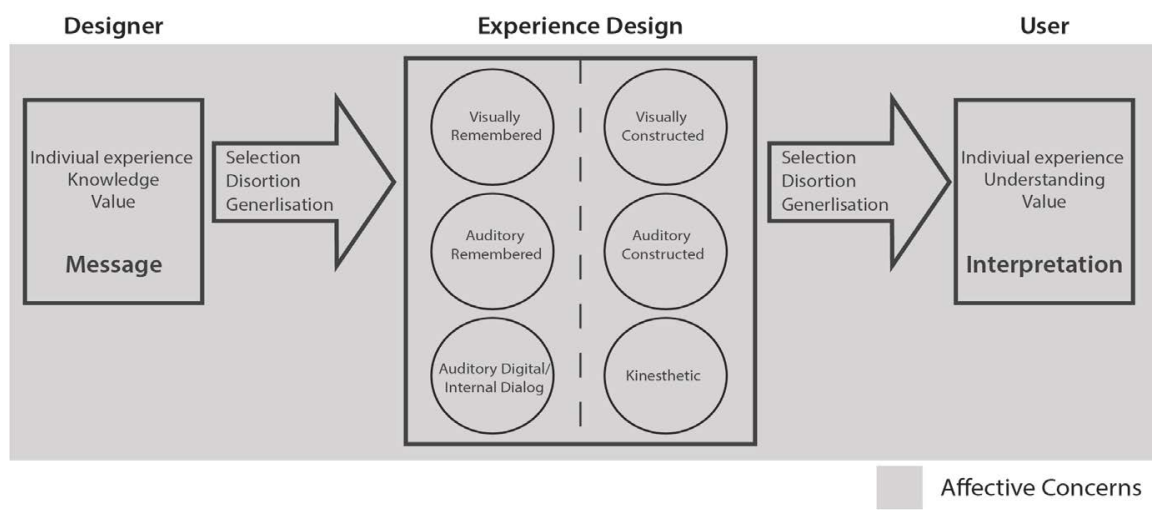

Figure 1. Model explaining how affective concern stimulations shape experience. 
Designers present a message based on their individual experience, knowledge, and value. Selection, distortion, and generalization a reapplied to reconstruct the elements from their long-term memory. Subsequently, they engage in the process of coding the visually remembered, auditory-remembered, and internal dialogues. When users consume the experience design, they obtain the constructed visual, auditory, and kinesthetic elements. Through the selection, distortion, and generalization aspects of the encoding process, the users' interpretations are generated.

\section{Guidelines for Generating User Experience with Affective Concern Stimulations}

On the basis of the literature review and the proposed model, guidelines for generating user experience with affective concerns are proposed:

- Define the main affective concern related to the experience to be shaped for users.

- Determine whether users have had any similar experience with this affective concern.

- Determine whether users have had any visual memory related to this affective concern.

- Determine whether users have had any auditory memory related to this affective concern.

- Determine whether any of the internal dialogues generated by the visual and auditory memories are related to this affective concern.

\section{Guidelines for Generating User Experience with Affective Concerns}

\subsection{Aim and Methodology}

To examine the accuracy of the proposed model and the effectiveness of the proposed guidelines, this study conducted a set of field observations and interviews with designers and users. The field observation was a structured observation. The participants were designers that were randomly invited from the Hong Kong design industry, all of whom had less than 1 year of working experience. They were divided into two teams and then assigned a design task.

A total of 100 local Hong Kong participants were invited to participate in this stage of the study. Each of the participants was asked to collect 50 samples of print material that they considered representative of experience design.

To understand how citizens identify the features of experience design, gaining input from a wide spectrum of citizens was crucial; consequently, the generalization of research participation was essential. Therefore, participants with different educational backgrounds and ages were recruited. The profile of the participants (Figure 2) is outlined as follows:

- Twenty of the participants were undergraduate design students.

- Twenty of the participants were randomly recruited members of the working class, aged between 30 and 40 years. 


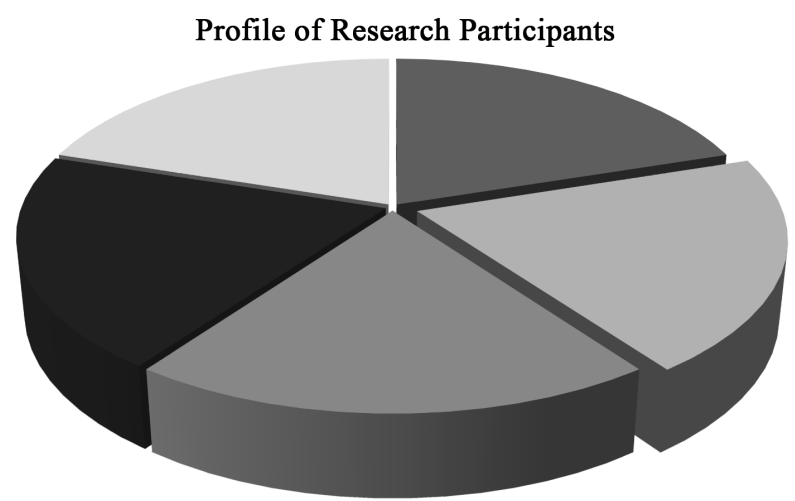

- Undergraduate Design Students

- Working Class (aged from 40-50)

Professional (aged from 40-50)
Working Class (aged from 30-40)

- Professional (aged from 30-40)

Figure 2. Background information on the recruited participants.

- Twenty of the participants were randomly recruited members of the working class, aged between 40 and 50 years.

- Twenty of the participants were randomly recruited professionals aged between 30 and 40 years.

- Twenty of the participants were randomly recruited professionals aged between 40 and 50 years.

\subsection{Procedures}

The study was conducted in two stages (Table 1). Stage 1 involved field observations, which examined the manipulation of the experience design process with and without the proposed guidelines for introducing affective concerns. The field observations assessed 30 designers and 100 users through a video-recorded interview. The 30 designers were separated into two groups: Design Team A and Design Team B. Design Team A followed the proposed guideline of introducing affective concerns (details of the guideline were mentioned above), whereas Design Team B did not.

Users assessed the experience design produced, and their assessments were recorded. Subsequently, the users' feedback was analyzed to determine whether the professionals' affective concerns were delivered effectively through the experience design. In Stage 1, some questions were posed to the designers during the design process to obtain their feedback:

1. What is the design objective for the project?

2. What do you expect the team to accomplish?

3. Approximately what percentage of the design objective has been accomplished?

4. On a scale of $1-100$, how close is the final outcome to your initial expectations?

In Stage 2, users were asked the following questions regarding their experience, to assess the experience design outcomes: 
Table 1. Research agenda.

\begin{tabular}{|c|c|c|}
\hline Stage & $\begin{array}{l}\text { Objective of the } \\
\text { corresponding stage }\end{array}$ & Methodology \\
\hline $\begin{array}{l}\text { Stage 1: } \\
\text { Field observation }\end{array}$ & $\begin{array}{l}\text { To observe the manipulating } \\
\text { of experience design process } \\
\text { with/without the Guideline of } \\
\text { introducing Affective Concerns }\end{array}$ & $\begin{array}{l}\quad \text { Design Team A } \\
\text {-15 designers worked } \\
\text { with the guideline of } \\
\text { introducing Affective Concerns } \\
\text { Design Team B } \\
\text {-15 designers worked } \\
\text { without the guideline of } \\
\text { introducing Affective Concerns }\end{array}$ \\
\hline $\begin{array}{l}\text { Stage } 2 \text { : } \\
\text { The assessment of } \\
\text { experience design } \\
\text { outcomes }\end{array}$ & $\begin{array}{l}\text { To discover whether the } \\
\text { participated designers' affective } \\
\text { concerns were delivered effectively } \\
\text { through the experience design. }\end{array}$ & $\begin{array}{l}\text {-100 users evaluated experience design } \\
\text {-compared the scores and } \\
\text { feedbacks from the users on the } \\
\text { two different design teams }\end{array}$ \\
\hline
\end{tabular}

1. Do you know the design objective for the project?

2. What did you expect the design to accomplish?

3. Approximately what percentage of the design objective has been accomplished?

4. On a scale of $1-100$, how close is the final outcome to your initial expectations?

\subsection{Results}

The 100 recruited users consumed the 30experience design outcomes and provided a score for each (100 marks as the highest and 1 mark as the lowest). The average score for the experience designs under the guidelines of introducing affective concerns (Team A) was 86 marks, while the average score for the experience designs not under the guidelines of introducing affective concerns (Team B) was 53 marks. The feedback provided by the users can be highlighted as follows. The users indicated that the human-centered solutions, which were generated under the affective concern guidelines, were much more enjoyable, because the presentations of visual and audio elements were considerably more effective in satisfying their needs. In addition, the field observation on the design process of the design teams revealed that Team A, which adopted the guidelines for introducing affective concerns, was much more effective in generating creative experience designs than was Team B (Tables 2-4).

\subsection{Discussion}

According to the participants' feedback, designers and users connected through the design experience. The affective concerns were operated and elicited by the perceived meaning of the designers and users in that specific time juncture. The participants described their experience according to the affective process presented in the literature. Their feedback provided evidence for corroborating the concept that individuals develop emotional experience as an integral element for configuring a situation in design experience. Individuals respond to affective 
Table 2. Percentage of matchingdesigner and user evaluations on the experience design.

\begin{tabular}{ccc}
\hline $\begin{array}{c}\text { The percentage of } \\
\text { matching designer } \\
\begin{array}{c}\text { and users' evaluations } \\
\text { on the experience design }\end{array}\end{array}$ & $\begin{array}{c}\text { Design outcomes from Team A } \\
\text { (Generated under the guideline of } \\
\text { introducing Affective Concerns) }\end{array}$ & $\begin{array}{c}\text { Design outcomes from Team B } \\
\text { (Generated without guideline of } \\
\text { introducing Affective Concerns) }\end{array}$ \\
\hline Average scores & 88 & 56 \\
\hline
\end{tabular}

Table 3. Percentage of the design objective accomplished.

\begin{tabular}{ccc}
\hline $\begin{array}{c}\text { The percentage of } \\
\text { the design } \\
\text { objective accomplished }\end{array}$ & $\begin{array}{c}\text { Design outcomes from Team A } \\
\text { (Generated under the guideline of } \\
\text { introducing Affective Concerns) }\end{array}$ & $\begin{array}{c}\text { Design outcomes from Team B } \\
\text { (Generated without guideline of } \\
\text { introducing Affective Concerns) }\end{array}$ \\
\hline Average scores & 86 & 53 \\
\hline
\end{tabular}

Table 4. Users' evaluations ofthe final outcome againsttheir initial expectations.

\begin{tabular}{ccc}
\hline $\begin{array}{c}\text { Users' evaluations } \\
\text { on the final outcome } \\
\text { to the initial expectations }\end{array}$ & $\begin{array}{c}\text { Design outcomes from Team A } \\
\text { (Generated under the guideline of } \\
\text { introducing Affective Concerns) }\end{array}$ & $\begin{array}{c}\text { Design outcomes from Team B } \\
\text { (Generated without guideline of } \\
\text { introducing Affective Concerns) }\end{array}$ \\
\hline Average scores & 78 & 46 \\
\hline
\end{tabular}

concerns that arise as they step into a situation. The individuals' feedback toward the emotions constitutes the affective elements, which drive their judgment and reactions during the design experience. The individuals subsequently categorize the affective experience, and this triggers further affective operation, thus shaping their long-term memory (based on the original experience). Comparing the proposed model and the participants' feedback revealed that both had similar flows, from pre-encounter "givens" to encounter, then to evaluations and further responses, in turn shaping the givens of subsequent encounters. Hence, the participants' feedback revealed the effectiveness and accuracy of the proposed model, as well as the effectiveness of the proposed guidelines.

\section{Conclusion}

Most current designs are aimed at achieving success in the market. However, the design industry is generally interested in creating designs that can connect with users. Hence, studies have investigated the experience of design consumption according to users' memory-based perceptions of the design. Specifically, the perception of the design is the key factor for creating connections and bonding. Nevertheless, not all designs could successfully connect with users and consequently create a valuable design experience. Therefore, researchers in the discipline of user experience have proposed that design connection could be generated through human-design interactions. Additional investigations have been conducted on user experience mechanisms including the roles of human needs, affective concerns, thoughts, and actions. Different senses such as audio and visual influence users' experience during design consumption. Such experiences generally influence users' satisfaction with the designs. This could thus provide an alternative to the existing design methods, which focus on satisfying design func- 
tions and often ignore the resulting user experience. Therefore, a shift in design focus, from function to experience, has been proposed. Studies have revealed that at the heart of experience, affective concerns have become a promising aspect and enhanced the influence of experience on an individual's memory. Consequently, affective concerns are a critical factor of experience perception. In this study, design and affective concerns were investigated to determine how designed solutions could intentionally elicit the affective concerns of users. A critical literature review was also undertaken to understand the state-of-the-art strategies in user experience design and to analyze, compare, and enhance existing knowledge. A set of guidelines for generating user experience with affective concerns was proposed.

Rather than designing to generate attractive outcomes, the focus was placed on providing proper design solutions for satisfying users' needs, further contributing to experience shaping. Designers are facing more difficulties than before. This study is the first to consider and apply affective concerns in experience design. The findings contribute primarily to developing affective concerns as the leading element in experience design. The proposed model was the preliminary concept to illustrate how affective concerns influence the users' responses. Further exploration on how affective concerns actually influence the users' decision making and responses with their physical expressions during the design experience in experience design field is needed. Also, as most of the participants in this study were Asian, it was limited to generalise the research result of this study to the worldwide users under the potential influence of cultural differences. Here is a need to conduct further investigation among the worldwide users about their affective concerns during their consumption in experience design.

\section{Acknowledgements}

The author thanks the editorial board for reviewing this research paper. The author also extends special gratitude to all participants of this study.

\section{References}

Arhippainen, L., \& Tahti, M. (2003). Empirical Evaluation of User Experience in Two Adaptive Mobile Application Prototypes. 2nd International Conference on Mobile ldots Proceedings (pp. 27-34).

Bandler, R., Grinder, J., Stair, V., \& Bateson, G. (2005). The Structure of Magic, Vol. 1: A Book about Language and Therapy. Mountain View, CA: Science and Behavior Books.

Craik, F., \& Lockhart, R. (1972). Levels of Processing: A Framework for Memory Research. Journal of Verbal Thinking and Verbal Behavior, 11, 671-684.

Faiola, A., \& Matei, S. A. (2005). Cultural Cognitive Style and Web Design: Beyond a Behavioral Inquiry of Computer-Mediated Communication. The Journal of Computer Mediated Communication, 11. http://jcmc.indiana.edu/vol11/issue1/faiola.html

Fogg, B. J. (2002). Stanford Guidelines for Web Credibility. A Research Summary from the Stanford Persuasive Technology Lab. Stanford University.

www.webcredibility.org/guidelines

Freud, S. (1937). Constructions in Analysis. 23, 256-269. 
Gobé, M. (2001). Emotional Branding: The New Paradigm for Connecting Brands to People. New York, NY: Allworth Press.

Gratch, J., \& Marsella, S. (2005). Some Lessons for Emotion Psychology for the Design of Lifelike Characters. Journal of Applied Artificial Intelligence, 19, 215-233.

Green, P. (2008). Iterative Design. Lecture Presented in Industrial and Operations Engineering 436 Human Factors in Computer Systems, University of Michigan, Ann Arbor, MI.

Hassenzahl, M. (2006). Hedonic, Emotional and Experiential Perspectives on Product Quality. In C. Ghaoui (Ed.), Encyclopedia of Human Computer Interaction (pp. 266-272). London, UK: Idea Group Reference.

Hekkert, P., \& Schifferstein, H. N. J. (2008). Introducing Product Experience. In H. N. J. Schiffer-Stein, \& P. Hekkert (Eds.), Product Experience (pp. 1-8). Amsterdam: Elsevier.

Kelly, D. (2009). Methods for Evaluating Interactive Information Retrieval Systems with Users. Foundations and Trends in Information Retrieval, 3, 1-224.

Lockner, D., Bonnardel, N., Bouchard, C., \& Rieuf, V. (2014). Emotion and Interface Design. In G. J. Yomg, \& S. Choi (Eds.), Proceedings of the AHFE Conference 2014 (pp. 33-40). New York, NY: ACM. https://doi.org/10.1145/2671470.2671475

Longueville, B., Le Cardinal, J., Bocquet, J., \& Daneau, P. (2003). Towards a Project Memory for Innovative Product Design: A Decision Making Process Model. In A. Folkeson, K. Gralen, M. Norell, \& U. Sellgren (Eds.), DS 31: Proceedings of ICED 03, the 14th International Conference on Engineering Design, Stockholm (pp. 457-458). New York, NY, USA: ACM.

Mahlke, S., \& Thuring, M. (2007). Studying Antecedents of Emotional Experiences in Interactive Contexts. In M. B. Rosson, \& D. Gilmore (Eds.), Proceedings of the SIGCHI conference on Human Factors in Computing Systems (pp. 915-918). New York, NY: ACM. https://doi.org/10.1145/1240624.1240762

McCarthy, J., \& Wright, P. (2004). Technology as Experience. London: The MIT Press.

McCartney, T., \& McCartney, K. (2014). The NLP Practitioner: A Practitioners Toolkit. Raleigh, NC: Lulu Publishing Services.

Nielsen, J. (1994). Usability Engineering (p. 165). Cambridge, MA: Academic Press Inc.

Rosenberg, E. L. (1998). Levels of Analysis and the Organization of Affect. Review of General Psychology, 2, 247-270. https://doi.org/10.1037/1089-2680.2.3.247

Scherer, K. R. (1997). The Role of Culture in Emotion-Antecedent Appraisal. Journal of Personality and Social Psychology, 73, 902-922. https://doi.org/10.1037/0022-3514.73.5.902

Schenkman, B. N., \& Jonsson, F. U. (2000). Aesthetics and Preferences of Web Pages. Behaviour \& Information Technology, 19, 367-377. https://doi.org/10.1080/014492900750000063

Watzman, S. (2003). Visual Design Principles for Usable Interfaces. In J. A. Jacko, \& A. Sears (Eds.), The Human-Computer Interaction Handbook: Fundamentals, Evolving Technologies, and Emerging Applications (pp. 263-285). Mahwah, NJ: Erlbaum.

Zettl, H. (1990). Sight Sound Motion: Applied Media Aesthetics (2nd ed.). Belmont, CA: Wadsworth Publishing Company. 
Submit or recommend next manuscript to SCIRP and we will provide best service for you:

Accepting pre-submission inquiries through Email, Facebook, LinkedIn, Twitter, etc. A wide selection of journals (inclusive of 9 subjects, more than 200 journals)

Providing 24-hour high-quality service

User-friendly online submission system

Fair and swift peer-review system

Efficient typesetting and proofreading procedure

Display of the result of downloads and visits, as well as the number of cited articles Maximum dissemination of your research work

Submit your manuscript at: http://papersubmission.scirp.org/

Or contact adr@scirp.org 